\title{
TÉCNICA SIMPLES DE MARCAÇÃO EXTERNA DE REPRODUTORES DE TILÁPIA NILÓTICA (Oreochromis niloticus) ${ }^{1}$
}

\author{
SIMPLE TECNIQUE FOR EXTERNAL MARKING OF \\ NILE TILAPIA'S BROODSTOCK (Oreochromis niloticus)
}

\author{
Ema Magalhães Leboute ${ }^{2}$ Luis Orlando Bertolla Afonso ${ }^{3}$ Marco Aurélio Rotta ${ }^{4}$
}

\begin{abstract}
Com a finalidade de organizar um programa de
controle da reprodução de tilápia nilótica (Oreochromis RESUMO niloticus) em laboratório, foi desenvolvida uma técnica na qual foi utilizada pérolas de cerâmica presas à musculatura dorsal do animal por transfixação com um fio sintético flexível. Foram usados 60 peixes com peso médio de $12 \mathrm{~g}$ e 60 com peso médio de 19g. A marcação foi feita em três posições: frontal $(F)$, mediana (M) e caudal (C). Diferentes combinações de três pérolas coloridas foram fixadas do lado direito (definindo o número), e eram ligadas a uma única pérola do lado esquerdo (definido o sexo), deixando-se cerca de $1,5 \mathrm{~cm}$ de folga no fio para não causar prejuízo ao crescimento. Os animais foram identificados e pesados individualmente aos 30, 60 e 130 dias após a cirurgia de transfixação. Os resultados indicaram que as posições $F$ e $M$ permitiram crescimento e comportamento reprodutivo normais, $e$ na posição $C$ houve mortalidade e perda do marcador. Recomenda-se como melhor posição a $M$, ou então a intermediária entre $F$ e $M$.
\end{abstract}

Palavras-chave: reprodução, controle, melhoramento.

\section{SUMMARY}

With the goal of organizing a control program of Nile tilapia (Oreochromis niloticus) reproduction in laboratory, a tecnique with ceramic pearls held on dorsal musculature by transfixion with flexible sintetic string was developed. Sixty fishes with $12 \mathrm{~g}$ average weight and 60 with $19 \mathrm{~g}$ average weight were used. Marking was done on three positions: frontal $(F)$, median $(M)$, and caudal $(C)$. Different combinations of three collored pearls were fixed on the right side (defining number), and were linked to only one pearl in the left side (defining sex), with a slack of about $1.5 \mathrm{~cm}$ to prevent growth damage. The animals were individually identified and weigthed at 30,60 and 130 days after surgery. Results showed that both $F$ and $M$ positions allowed normal growth and reproductive behavior, whereas the $C$ position induced mortality and loss of marker in some specimens. The $M$ position is recomended as the best, or the intermediate between $F$ and $M$ positions.

Key words: reproduction, control, improvement.

Qualquer programa de melhoramento genético requer a identificação segura dos genitores. O manejo habitual para reproduzir em laboratório a tilápia nilótica (Oreochromis niloticus) consiste na organização de famílias em proporção de 3 a 5 fêmeas para 1 macho (AFONSO et. al., 1993b) mantidos em tanques individuais ou coletivos. Como a fêmea desta espécie incuba na boca seus ovos fertilizados e estes podem, sem prejuízo da eclodibilidade, serem retirados e incubados artificialmente (AFONSO et al., 1993a), a identificação das fêmeas com um mesmo macho torna possível acompanhar tanto o desempenho reprodutivo dos casais quanto a taxa de crescimento de seus descendentes. Diversas técnicas de marcação de peixes tem sido propostas (ARNOLD, 1996; THOMAS, 1975). Nos países onde a aquacultura está mais desenvolvida, encontra-se no mercado marcadores de material plástico ou metálico, de

\footnotetext{
${ }^{1}$ Trabalho desenvolvido no Setor de Aquacultura. (Financiamento CNPq).

${ }^{2}$ Professor Titular (Aposentado), Departamento de Zootecnia (DZ), Universidade Federal do Rio Grande do Sul (UFRGS).

${ }^{3}$ Professor Adjunto I, DZ / UFRGS.

${ }^{4}$ Aluno de Mestrado do Programa de Pós-graduação em Zootecnia, UFRGS. Rua 21 de setembro, 1880, Bairro Nossa Senhora de Fátima, CP 109, 79320-900 Corumbá, MS. E-mail: marcoarotta@yahoo.com.br. Autor para correspondência.
} 
cores variadas, já numerados, os quais são fixados à musculatura dos animais através do disparo feito com um aplicador apropriado. Estes marcadores externos têm boa duração, mas podem ser expelidos pelo tecido muscular. O objetivo desse trabalho foi desenvolver uma técnica de marcação externa permanente, de fácil identificação e de baixo custo, realizada com materiais disponíveis no comércio local, e que, ao mesmo tempo, não afetasse nem a natação nem o comportamento sexual no acasalamento, além de possibilitar a observação dos animais dentro de aquários com águas cristalinas.

De uma população de 443 fêmeas sexadas visualmente, nascidas no laboratório, com 6 meses de idade e criadas em alta densidade (AFONSO \& LEBOUTE, 1993), foram selecionadas 60 peixes com peso médio de $12 \mathrm{~g}$ e $60 \mathrm{com}$ peso médio de $19 \mathrm{~g}$. Com a finalidade de estudar a posição mais favorável para a colocação do marcador, cada um dos grupos de peso foi subdividido em três sub-grupos de 20 animais, que foram marcados nas posições: $\mathrm{F}$ - na altura do $3^{\circ}$ raio da nadadeira dorsal; $\mathrm{M}$ - na altura da metade da nadadeira dorsal; e $\mathrm{C}$ - junto aos últimos raios da nadadeira dorsal. $\mathrm{O}$ marcador constituiu-se de pérolas de cerâmica de 4 cores, cuja combinação resultou num código numérico. Três pérolas ficavam pendentes do lado direito do corpo e eram fixadas por um fio sintético flexível (APTAN 60) que as ligava a uma única pérola ao lado esquerdo, cuja cor definia o sexo. Foi deixado cerca de $1,5 \mathrm{~cm}$ de folga no fio para não prejudicar o crescimento do animal. Para o procedimento de marcação os animais, em jejum de 24 horas, foram anestesiados com MS 222 $(100 \mathrm{mg} / \ell)$. O local a ser marcado foi desinfetado com tintura de iodo, sendo então transfixados com auxílio de uma agulha de costura. A marca numérica foi presa através de pontos de fixação na pérola do lado esquerdo do animal. Durante esses procedimentos, apenas dois animais apresentaram pequeno sangramento. Logo após a cirurgia eles foram colocados em caixas de cimento amianto de $80 \ell$, na densidade de 10 animais por caixa, para fins de observação do período pós-cirúrgico. A alimentação voltou a ser fornecida normalmente 24 horas após a cirurgia. Após 7 dias, os animais foram transferidos para uma caixa de 1.000 $\ell$. Nos animais foram feitas observações quanto à sobrevivência, natação, agressões, permanência do marcador e facilidade de identificação. Os animais foram pesados individualmente aos 30, 60 e 130 dias após a cirurgia. Também foi observado, aos 135 dias, o comportamento reprodutivo de 14 animais colocados em caixas de $1.000 \ell$.

Na tabela 1, são mostrados os resultados obtidos quanto à persistência do marcador colocado e ao desenvolvimento em peso vivo. Pode ser observado que os animais com maior peso inicial duplicaram seu peso médio ao final do período experimental, enquanto os menores triplicaram de peso. $\mathrm{O}$ estresse da marcação não afetou o crescimento ao longo do período, e o aparente ganho compensatório de peso dos animais menores deveuse à menor densidade em que foram estocados (antes do ato cirúrgico encontravam-se na densidade de 0,4

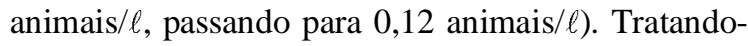
se de uma espécie territorial, a menor densidade usada deve ter contribuído para diminuir o estresse social (VOLPATO \& FERNANDES, 1994), possibilitando a melhor expressão de sua capacidade de ganho em peso individual. As posições de marcação F e M mostraram igual capacidade de permanência. A morte de um único peixe grande do tratamento $\mathrm{F}$ deveu-se a seu salto para fora do tanque. As perdas nos tratamentos F e M, tanto para animais grandes como pequenos, ocorreram pela expulsão dos marcadores, sem a morte dos animais. Não foi encontrada lesão no local onde o marcador foi aplicado. Os marcadores, quando expelidos, foram encontrados inteiros, mostrando que a ligação entre eles com o fio APTAN 60 não se rompeu. Os animais pequenos marcados na posição $\mathrm{C}$ tiveram $50 \%$ de conservação do marcador e apresentaram $45 \%$ de mortalidade na primeira semana após o ato cirúrgico, como conseqüência de severas necroses no

Tabela 1 - Número de animais que conservaram o marcador e peso médio (g) de cada grupo durante o período experimental.

\begin{tabular}{|c|c|c|c|c|c|c|c|c|}
\hline \multirow[t]{3}{*}{ Posição da Marcação } & \multicolumn{8}{|c|}{ Tempo após a cirurgia (dias) } \\
\hline & \multicolumn{2}{|r|}{0} & \multicolumn{2}{|r|}{30} & \multicolumn{2}{|c|}{60} & \multicolumn{2}{|c|}{130} \\
\hline & No. & Peso & No. & Peso & No. & Peso & No. & Peso \\
\hline \multicolumn{9}{|l|}{ Animais Grandes } \\
\hline $\mathrm{F}$ & 20 & 20,32 & 20 & 27,07 & 19 & 30,96 & 19 & 48,16 \\
\hline M & 20 & 17,94 & 20 & 24,37 & 20 & 26,38 & 19 & 38,55 \\
\hline $\mathrm{C}$ & 20 & 18,74 & 18 & 23,91 & 9 & 25,79 & 1 & 40,45 \\
\hline Média & & 19,00 & & 25,11 & & 27,71 & & 42,39 \\
\hline \multicolumn{9}{|l|}{ Animais Pequenos } \\
\hline $\mathrm{F}$ & 20 & 12,40 & 20 & 19,81 & 20 & 24,22 & 19 & 38,77 \\
\hline M & 20 & 12,91 & 19 & 19,84 & 18 & 22,05 & 18 & 36,79 \\
\hline $\mathrm{C}$ & 20 & 12,62 & 10 & 18,78 & 9 & 21,20 & 3 & 43,20 \\
\hline Média & & 12,64 & & 19,47 & & 22,49 & & 39,59 \\
\hline
\end{tabular}

$\mathrm{F}=$ frontal; $\mathrm{M}=$ mediana $; \mathrm{C}=$ caudal 
local da cirurgia. Esse problema foi atribuído ao fato de que as pérolas colocadas nessa posição serviram como atrativo para o ataque por outros peixes. Esta posição resultou, na prática, em $90 \%$ de perdas do marcador. Os quatro animais que perderam o marcador e sobreviveram, apresentaram cicatrizes visíveis na posição da marcação. Após três a quatro dias da marcação, os animais voltaram a nadar equilibradamente. Durante as pesagens foi observado que 4 animais marcados na posição $\mathrm{F}$ apresentaram as 3 pérolas do lado direito dentro da guelra. Já na última biometria, 3 animais marcados na posição $F$ tiveram a pérola única do lado esquerdo incrustrada na pele, e a movimentação do marcador provocou um leve sangramento, devido ao uso de fio curto. Os animais que conservaram o marcador formaram um canal de pele no tecido onde o fio foi transpassado, podendo o marcador ser manuseado sem provocar sangramento. Após 5 dias da última pesagem, 14 animais dos tratamentos $\mathrm{F}$ e $\mathrm{M}$ foram colocados em um tanque de $1.000 \ell$. No dia seguinte, foi observada a construção de ninhos e comportamento de corte e acasalamento normais. É possível marcar de modo permanente tilápias nilóticas a partir de $12 \mathrm{~g}$ de peso vivo, utilizando pérolas coloridas de cerâmica ligadas por um fio sintético flexível, sem causar prejuízo às atividades de locomoção, reprodução e crescimento. A marcação deve ser feita na musculatura dorsal, na posição média da nadadeira. Para evitar a expulsão do marcador faz-se necessário padronizar a posição da transfixação em relação ao dorso do animal, como também deixar uma folga no fio para permitir o crescimento normal.

\section{REFERÊNCIAS BIBLIOGRÁFICAS}

AFONSO, L.O.B.; LEBOUTE, E.M. Método de sexagem visual de alevinos de tilápia nilótica, Oreochromis niloticus. In: ENCONTRO RIO-GRANDENSE DE TÉCNICOS EM AQÜICUlTURA, 4, 1993, Porto Alegre, RS. Anais... Porto Alegre: UFRGS, 1993. p.100-103.

AFONSO, L.O.B.; GUDDE, D.H.; LEBOUTE, E.M., $\boldsymbol{e}$ t al. Método para a incubação artificial de ovos de tilápia nilótica, (Oreochromis niloticus). Rev Soc Bras Zootec, Viçosa, v.22, n.3, p.502-505, 1993a.

AFONSO, L.O.B.; SOUZA, S.M.G.; LEBOUTE, E.M. Comportamento e desempenho reprodutivo da tilápia nilótica, Oreochromis niloticus, em condições de laboratório. In: ENCONTRO RIO-GRANDENSE DE TÉCNICOS EM AQÜICULTURA, 4, 1993, Porto Alegre, RS. Anais... Porto Alegre: UFRGS, 1993b. p.83-88.

ARNOLD, D.E. Marking fish with dyes and other chemicals. Techical Paper US Bureau of Sport Fisheries and Wildlife, v.10, p.3-44, 1966.

THOMAS, A.E. Marking channel catfish with silver nitrate. Prog Fish-Cult, Bethesda, v.37, p.250-252, 1975.

VOLPATO, G.L.; FERNANDES, M.O. Social control of growth in fish. Brazilian J Med Biol Res, São Paulo, v.27, p.797-781, 1994. 